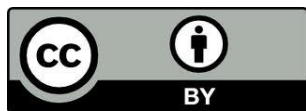

\title{
HERESIA: DESVIO DOUTRINÁRIO OU AFIRMAÇÃO DO CONTRA-PODER?
}

\author{
Heresy: bias against the claim or doctrinal-power?
}

\author{
Geraldo Pieroni \\ Doutor em História pela Université Paris-Sorbonne (Paris IV). Coordenador de Pesquisa e \\ Iniciação Científica e Editoração na Universidade Tuiuti do Paraná. Professor-pesquisador no \\ Programa de Pós-Graduação Strictu Sensu em Educação na UTP
}

RESUMO: Historicamente, o fato de a heresia ter tido um papel positivo para a própria conscientização ou esclarecimento da ortodoxia, já havia sido evidenciado por santo Agostinho na obra De Vera religione. Ele reconheceu a importância do herege ao incentivar a "busca pela verdade". A heresia não contém somente conotações negativas. Na história da Igreja, houve heresias que, antes de serem qualificadas ou condenadas como tais, foram essenciais na trajetória da definição de um dogma. Este foi o ocorrido com a controvérsia ariana, que viu bispos e escolas teológicas inclinados a um lado ou a outro, mesmo depois do Concílio de Niceia o qual decidiu qual era a "verdadeira religião". Neste enfoque analisaremos alguns processos de hereges existentes no mundo luso-brasileiro nos quais os inquisidores classificaram como ações iníquas e maléficas. Na sala secreta do Tribunal lisboeta, eles consultaram os livros canônicos e os regimentos da Inquisição e comprovaram que estes heréticos haviam desviado da "autêntica doutrina" e, portanto deveriam pagar suas culpas. $\mathrm{O}$ valor da heresia consiste, sobretudo, segundo Mazzi, na libertação do domínio do sagrado, entendido como "abstração, separação e contraposição entre as várias dimensões da nossa existência". O sagrado se torna "projeção de uma angústia não resolvida, de uma ruptura interna, de uma falta de autonomia e, enfim, de uma alienação da própria subjetividade nas mãos do poder". A novidade para se estudar a religiosidade popular consiste em fazer da heresia a chave interpretativa da história. Representa uma negação doutrinal ou uma afirmação do contra-poder?

Palavras chave: heresias, feitiçaria, contra-poder

\begin{abstract}
Historically, the fact of heresy have had a positive role to own awareness or enlightenment of orthodoxy, had already been shown by St. Augustine in the work De Vera religione. He recognized the importance of the heretic to encourage the "search for truth". Heresy does not contain only negative connotations. In the history of the Church, there were heresies that before being qualified or condemned as such, were essential in the path of defining a dogma. This was what happened with the Arian controversy, which saw bishops and theological schools inclined to one side or the other, even after the Council of Nicaea which decided what was the "true religion." In this approach we analyze some existing processes heretics in Luso-Brazilian world in which the inquisitors classified as evil and wicked deeds. In the secret room of the Court of Lisbon, they consulted the canonical books and the regiments of the Inquisition and proved that these heretics had deviated from the "true doctrine" and therefore should pay their guilt. The value of heresy consists, mainly, according Mazzi, the liberation of the domain of the sacred, understood as "abstraction, separation and opposition between the various dimensions of our existence." The sacred becomes "projection of an unresolved anguish, an internal rupture, a lack of autonomy and ultimately a sale of subjectivity itself in the hands of power." New for studying the popular religiosity consists in making the interpretative key of heresy in history. Represents a denial or a doctrinal statement of counter-power?
\end{abstract}

Keywords: heresy, witchcraft, counter-power 
"A tradição gostaria que um discurso sobre a heresia começasse com a etimologia: do àiresis que significa escolha também entendido no sentido da mudança, transformação. Em seguida, passaria para a história, especialmente a história cristã, que no século IV (Concílio de Niceia, ano 325) inventou a contraposição entre ortodoxia e àiresis, que sobrevive até hoje, deixando um horrível rastro de sofrimento, humilhação, aniquilação, sangue e fogueiras. Para colocar fim a este senso comum, agora aberto a um significado que abrange também tudo aquilo que se apresenta ou é visto como "contra-corrente", "transgressão", "descontinuidade", não só no campo cultural mas também político, econômico ou até mesmo nos costumes. Gostaria que a minha reflexão fosse além desses conceitos tradicionais, sem, todavia ignorá-los, e aplicar à heresia algo como realidade positiva, dinâmica, força geradora em eterna expansão, alma da transformação cósmica, histórica e pessoal. Apresentamos a heresia como realidade contrária à outra força de oposição, ao poder, à estabilidade degenerativa em perene implosão". (Enzo Mazzi, 2010, p. 7)

Heresia - "escolha" ou "opção" - representa o conjunto de pensamento contrário a um credo ou sistema doutrinário organizado e reconhecido enquanto ortodoxia. $\mathrm{O}$ termo refere-se também a qualquer "desvio" de sistemas filosóficos instituídos, ideologias políticas, paradigmas científicos, movimentos artísticos, ou outros. Herege é aquele que se desvia da fé institucionalizada e heresiarca é aquele quem funda uma heresia.

Georges Duby descreve que "todo herético tornou-se tal por decisão das autoridades ortodoxas". Ele é antes de tudo "um herético aos olhos dos outros" (1990, p. 177). Ninguém é herético em si mesmo. Esta qualificação pejorativa nada mais é do que o determinismo de alguém que, do seu próprio ponto de vista, julgava trilhar o caminho correto. Assim sendo, o réu é designado "herege" somente porque uma autoridade, investida de poder eclesiástico (inquisidores) e institucional (Santo Ofício) qualificou o seu comportamento, suas ideias e práticas como discordantes, contrárias a um tradicionalismo oficial que se auto-impetrava como única via correta (BARROS, 2007/2008, p. 125).

Existem os heréticos malleficarum? Existem as feiticeiras? Questionavam retoricamente os autores do Manual dos Inquisidores publicado em 1494. Embora 
muitos acusados fossem do sexo masculino, o texto deste documento trata a feitiçaria como manifestação de heresia tipicamente feminina; o seu conteúdo não faz referência ao sexo masculino; é expressão literária e normativa referente à mulher: É preciso dizer antes de tudo que mulheres celeradas, pervertidas por Satanás, dizem-se e crêem-se seduzidas por mentiras e enganos dos demônios (...) e as mulheres que sustentam tais propósitos? Voltemos às feiticeiras, essas mulheres que crêem se encontrar à noite com inúmeras outras mulheres ao lado de Diana, deusa dos pagãos" (LE DICTIONNAIRE DES INQUISITEURS, 1494, p. 410).

A cultura dos inquisidores, herança do Gênesis bíblico e da tradição exegética cristalizada no medievo, enxergava as mulheres enquanto malae bestiae. Elas são facilmente seduzidas por Satanás, pois não são "da mesma terra de que Adão foi moldado" e elas não são feitas à imagem de Deus (LE DICTIONNAIRE DES INQUISITEURS, 1494, p. 208). Para estes juízes da fé, a mulher é naturalmente perversa, uma presa que, sem dificuldade, cai nas ilusões do demônio.

O misógino pensamento inquisitorial relacionado às práticas diabólicas encontra-se registradas nos muitos tratados demonológicos publicados na Idade Média, no entanto a construção do célebre mito europeu das noivas de satanás relacionado às feiticeiras detentoras de poderes extraordinários e diabólicos, não corresponde, em geral, à feitiçaria perseguida pela Inquisição em Portugal. Os processos, grosso modo, não revelam o mito demonológico da imagem da feiticeira noturna que se transforma em ave de rapina, que voa vociferando medonhas blasfêmias, e que entra nas casas para devorar as inocentes criançinhas (SALLMANN, 1989, p. 27). As acusadas raramente confessam uma participação no sabá - festim profano e orgíaco. Elas negam, com freqüência, o pacto demoníaco, mesmo que a comunicação com o diabo seja reconhecida em quase todas as confissões (BETTENCOURT, 1987) ${ }^{1}$.

A maioria das feiticeiras portuguesas não se manifestava como mulheres submissas a satanás, no sentido pleno da palavra. Elas não eram suas servidoras incondicionais, suas mensageiras fiéis até as últimas conseqüências como aqueles dos parâmetros definidos pelo Malleus Maleficarum. Porém, não se pode negar a presença de alguns elementos "sabáticos" nas atitudes das condenadas. Os inquisidores, oportunamente, em suas minuciosas sindicâncias, encontravam indícios evidentes de

\footnotetext{
${ }^{1} \mathrm{O}$ autor afirma que, em Portugal, o sabá muito raramente manifestava-se de maneira articulada.
} 
participação no festim noturno, aos quais os demonólogos chamavam de sabá dos bruxos.

De acordo com Carlo Ginzburg, a seqüência que conduziu à sedimentação da imagem do sabá elaborada por juízes e inquisidores manifesta variantes específicas dependendo dos atores, tempos e lugares (2001, p. 17). Rituais heréticos carregados de elementos heterodoxos foram realizados para adorar e render culto ao diabo. A guisa de exemplo cito o caso de Margarida Gonçalves, a qual, segundo os inquisidores, afastouse "de nossa santa fé católica" fazendo um pacto com o diabo, o qual lhe apareceu pela primeira vez sob o aspecto de um "mancebo" vestido de preto. Satanás propôs torná-la muito rica e salvar-lhe a alma, mas com a condição de que ela o adorasse. No seu processo consta que ela tinha um instinto diabólico, negligenciava a crença em Deus desacreditando na sua salvação. Ajoelhada ela adorava o diabo dizendo que somente ele tinha poderes divinos. Além do mais, à noite, Margarida, juntamente com outras mulheres, saíam descabeladas, com espetos de ferro nas mãos e, num determinado lugar, os espíritos do mal lhe apareciam incorporados em jovens rapazes com os quais elas tinham encontros carnais. Presa, Margarida Gonçalves foi severamente admoestada. Aos prantos pediu perdão e misericórdia, mostrando sinais de arrependimento. Devido ao seu remorso, ela foi recebida novamente no seio da Igreja. No dia 4 de maio de 1624 , ela saiu penitente no auto da fé; vestia o sambenito (a túnica penitencial); foi condenada a três anos de degredo para as terras brasílicas e proibida, para sempre, de voltar para sua cidade de origem (IAN/TT, Inquisição de Coimbra, processo 6808).

Como descrito nos exemplos acima citados, existia um específico protótipo que revestia as feiticeiras com alegorias obscuras e hostis, próximas ao grotesco: no imaginário dos inquisidores elas representavam um mundo ao avesso que invertia a lógica doutrinal da Igreja deslocando o olhar do Alto Divino para o Baixo Infernal.

Mikhail Bakhtin (1987) teoriza com perspicácia algumas características que são, de certo modo, percebíveis à análise deste nosso texto no sentido que para ele o carnaval é uma experiência que decorre de maneira inversa a certo modo de vida, o qual é comumente preestabelecido por determinada perspectiva da práxis cultural. Desta maneira, um mundo adverso no qual as normas que o regem estão temporariamente suspensas e as leis e as hierarquias que o organizam são invertidas, de modo que as distâncias firmemente estabelecidas e preservadas pelas convenções são abolidas 
(LOPES, 2003, p. 77). O mesmo podemos aplicar às práticas de feitiçaria que provocavam a ruptura de todas as regras sociais e culturais do regime em vigor: um mundo não oficial que contrasta com a visão preponderante da Igreja e do Estado, principais representantes da cultura oficial (SANTOS, 2008, p. 182).

Com referência aos célebres sabás noturnos - as orgias das bruxas - que se tornaram alvo do ataque à bruxaria a partir do momento em que esse fenômeno obteve a condição de heresia”, Mircea Eliade explica que

"Há uns oitenta anos atrás, o problema das origens da bruxaria parecia definitivamente solucionado. Segundo Hansen; a perseguição epidêmica dos mágicos e bruxas é um grande produto da tecnologia medieval, da organização eclesiástica e dos julgamentos mágicos levados a efeito pelo Papado e pela Inquisição (...) Também Lea chegou à conclusão de que foi a Inquisição, e não as bruxas, que inventou o conceito de bruxaria. Dentro desse conceito, aquele pesquisador datou as atividades de bruxaria como tendo se iniciado nos meados do século XIV $(1979, \text { p. } 75)^{2}$

A invenção deste modelo de feiticeira assustadora cujos poderes malleus maleficarum são temidos por toda a população, talvez possa ser percebido mais claramente no processo inquisitorial de Maria Simões, alcunhada de "a Branca". O povo da redondeza a considerava uma feiticeira poderosa. A população de Casas Novas, paróquia de São Marinho do Bispo, distrito de Coimbra, tinha muito medo de seus sortilégios, os quais podiam arruinar todos aqueles que não faziam o que ela queria.

Se Maria Simões fez realmente um pacto com o diabo, como consta no seu processo, ela o traiu dizendo que não se afastara da fé católica e que jamais fizera um pacto demoníaco (IAN/TT, Inquisição de Évora, processo 6823). Bruxa ou feiticeira, nos julgamentos inquisitoriais, significava pacto com o demônio. Sendo assim, todos foram condenados. Diante dos inquisidores, Maria Simões negou sua aliança com o diabo, dizendo que ela era uma boa cristã. O poderoso príncipe das trevas foi muitas vezes traído pelas feiticeiras as quais, durante o desenrolar dos processos, arrependiamse de seus erros e pediam, em lágrimas, perdão pelos seus pecados. Diante das pressões

\footnotetext{
${ }^{2}$ HANSEN, Joseph. Zauberwahn, Inquisition and Hexenprozess in Mittelalterand die Enstehung der grossen Hexenverfolgung. Munique: 1900 (reed.Munique,1964); LEA, H. C. The History of the Inquisiton in the Middle Ages. Nova Iorque: 1883. 3 v. (reed. Nova Iorque, 1957).
} 
dos inquisidores, nossas feiticeiras portuguesas, contrariamente ao arquétipo comum, mostravam-se choronas e lastimosas, bem como suplicavam, humildemente, por misericórdia, gritando pelos santos de sua devoção jurando fidelidade à Igreja católica. Para evitar a fogueira elas não podiam agir de outra forma.

Certas acusadas, face aos juízes inquisitoriais, afirmavam que não sabiam que estavam sendo iludidas por satanás. Ingenuidade ou esperteza? Freqüentemente, elas são realmente ignorantes com relação à fé católica; entretanto, diante dos juízes e das ameaças de pesados castigos, às vezes, fingem-se de ingênuas. Os inquisidores não se deixavam impressionar pelos comportamentos das acusadas durante os interrogatórios, pois conheciam muito bem "as dez astúcias dos hereges para responder sem confessar", o que Eymerich judicialmente detalhou em seu Manual dos Inquisidores (MANUEL DES INQUISITEUS, 1376 e 1578).

Embate evidente entre duas visões de mundo radicalmente opostas. De um lado, a concepção erudita dos juristas e teólogos; e do outro, a da cultura popular do povo supersticioso. Nesta luta as rés não tinham a mínima chance de saírem ilesas.

As histórias macabras, os sortilégios profanos e as curas supersticiosas, aos olhos da lógica inquisitorial, revelavam pelo menos dois pontos cruciais para a condenação das feiticeiras: a negação da fé católica e a invocação ou pacto com o demônio. Enquanto pivô da ordem cósmica, Deus era ameaçado pelas feiticeiras que anunciavam a vitória do anjo do mal num "mundo perverso" (DELUMEAU, 1983, p. 143). Mais ou menos conscientes, ou totalmente inconscientes, a ínfima infração à fé católica já era um sacrilégio, e os sábios clérigos do Santo Ofício sabiam que um herege é também aquele que se afasta, mesmo ligeiramente, do depósito da fé (DICTIONNAIRE DES INQUISITEURS, 1494, p. 239); "mesmo ligeiramente", explica o Dicionário dos Inquisidores. Era impossível não encontrar o mínimo de heresia em qualquer dos suspeitos que caíam nas redes do Santo Ofício.

Encurraladas entre dois discursos opostos: o dos padres inquisitoriais que propunham a salvação da alma, e; as tentações sedutoras do demônio, que oferecia o alívio de todas as aflições terrestres. Estas mulheres, assustadas, aceitavam as condições de seus carrascos renegando o diabo e prometendo lealdade à fé católica.

Como visto até aqui, o "imaculado" torna-se oficial; o "impuro" além de marginalizado é perseguido. O sagrado e o profano constituem em maneiras de ser no 
mundo que permitem ao homem se posicionar diante da própria existência, quer seja a partir da mais elementar até as mais elevadas manifestações. Nessas manifestações haveria uma ordem de realidade que não pertenceria ao mundo material e que criaria um elo entre a transcendência e a sua materialidade, pois o ser religioso, ao sacralizar o mundo, distinguiria o espaço sagrado dos outros, que por não serem sagrados, se apresentam disformes e sem sentido.

No conjunto das manifestações religiosas do Brasil Colônia, para identificar àquelas referentes à religiosidade instituída e as demais que fugiam do controle oficial consideradas práticas religiosas heterodoxas -, o entendimento do discurso e à sua circularidade de Mikhail Bakhtin (2008), é fundamental. O autor enfoca de que maneira a cultura popular foi compreendida por um intelectual da dimensão de Rabelais. Para Bakhtin, eram os membros das elites que conseguiam captar os costumes das classes populares, os elementos que lhes eram comuns. Ele explica a cultura medieval e renascentista pelo viés da obra de Rabelais, o qual sendo protagonista da época do Renascimento escreveu sobre os vários costumes da sociedade em que ele vivia.

Segundo Bakhtin as classes subalternas possuíam uma visão do mundo que se contrapunha ao dogmatismo e a austeridade cultural das classes dominantes, sobretudo quando estas "culturas subalternas" expressavam suas idéias e anseios de forma burlesca e cômica. Era a carnavalização dos valores da elite medieval. Mas, mesmo assim, essa elite era a única capaz de criar modelos a serem seguidos pela plebe "rude e ignara", formando uma mentalidade coletiva e interclassista, que, de certa forma não sofria a ação das massas a não ser pela sua inversão carnavalizante.

Continuando as análises de Mikhail Bakhtin, o historiador Carlo Ginzburg (1987), ampliaria o conceito de cultura popular para uma discussão sobre o processo de circularidade cultural. Historiador, antropólogo e um dos pioneiros no estudo da microhistória, a partir de uma exploração minuciosa das fontes, investiga pelo filtro de Menocchio, o moleiro de Friuli e sua incrível cosmogonia, a relação entre cultura popular e cultura erudita, no século XVI e discute até que ponto a primeira é subordinada à segunda.

Assim, Menocchio tornou-se o porta-voz de uma cultura popular, pois retirava da leitura dos livros apenas o que lhe interessava para sustentar suas idéias, e construía uma rede que interpunha as palavras escritas com as dele que refletia uma cultura oral, 
conforme suas antigas convicções e que induziu Menocchio a formular para si, para seus conhecidos e depois para os juízes as opiniões que saíam de sua própria cabeça.

Neste contexto permeado de conceitos binários referentes à ordem e a desordem, o clerical e o profano, o puro e o impuro, pode-se perceber que a contra ordem manifestada na heresia torna-se uma chave para reler a História. $\mathrm{O}$ estudo sobre os desvios heterodoxos considerados heréticos ganhou recentemente, uma análise muito interessante e ousada. Refiro-me ao livro de Enzo Mazzi intitulado "Il valore dell'eresia" (2010). O autor italiano constrói um discurso insólito a respeito desta temática. Ele inicia o seu texto examinando a heresia sob o olhar pelo qual a imposição da ortodoxia considerou como um desvio, imperfeição, perversão de uma verdade considerada absoluta. A intenção Mazzi vai muito além deste pressuposto consuetudinário. Ele não negligencia este aspecto, no entanto apresenta a heresia como realidade positiva, dinâmica, um contra ideia ou potência geradora de expansão, avessa à uma outra força oposta edificada pelo poder, a estabilidade, o conformismo e a hierarquia. Enzo Mazzi considera as opiniões diferentes ou antagônicas como um vigor pleno de vitalidade e cita exemplos historicamente dinâmicos tais como Giordano Bruno, Savonarola e Gioacchino Da Fiore, chegando até mesmo à Teilhard De Chardin para, em seguida, analisar a potência herética que se debate, ainda hoje, contra a lógica do poder e as imposições inquisitoriais que ganham novos impulsos no mundo contemporâneo.

Historicamente, o fato de a heresia ter tido um papel positivo para a própria conscientização ou esclarecimento da ortodoxia, já havia sido evidenciado por santo Agostinho n "De vera religione". Ele reconhece a importância que os hereges tiveram ao incentivar a "busca pela verdade". A heresia também não pode ter só uma conotação negativa se, na história da Igreja, houve heresias que, antes de serem qualificadas ou condenadas como tais, não eram outra coisa que um dos possíveis caminhos na definição do dogma: como ocorreu com a controvérsia ariana, que viu Igrejas inteiras e bispos e escolas teológicas inclinados a um lado ou a outro, mesmo depois do Concílio de Niceia, que decidiu qual era a verdadeira religião (RANIERO, 2010).

O valor da heresia consiste, segundo Mazzi, na libertação do domínio do sagrado, entendido como "abstração, separação e contraposição entre as várias dimensões da nossa existência". O sagrado se torna "projeção de uma angústia não 
resolvida, de uma ruptura interna, de uma falta de autonomia e, enfim, de uma alienação da própria subjetividade nas mãos do poder" (GIGANTE, 2011).

Neste sentido, o poder, considerado enquanto essência de "governamentalidade" é repensado por Foucault "como um domínio de relações estratégicas entre indivíduos ou grupos - relações que têm como questão central a conduta do outro ou dos outros, e que podem recorrer a técnicas e procedimentos diversos, dependendo dos casos, dos quadros institucionais em que ela se desenvolve, dos grupos sociais ou das épocas" (1997). As múltiplas maneiras do exercício da coerção estão historicamente presentes em todas as sociedades nas quais as autoridades públicas estabelecem suas jurisdições e utilizam os mais variados procedimentos punitivos. As leis são filhas do seu tempo e, por conseguinte, cada época legitima diferentemente o seu poder. No entanto o Leviatã, o estado soberano e centralizador, preconizado por Thomas Hobbes, não é a única instituição detentora do poder. Foucault aponta a existência de uma pluralidade de micro poderes, ultrapassando o consentimento de outorgar "um privilégio à lei como manifestação de poder". Ele sugere que se faça a tentativa de determinar as diferentes "técnicas de coerção" que operam na sociedade. (FOUCAULT, 1997, p. 71).

O ponto de novidade para se estudar a circularidade da religiosidade popular incide em fazer da heresia a chave interpretativa da história, uma manifestação do contra-poder diante do determinismo religioso enquanto paradigma da verdade.

Referênciais

BAKHTIN, Mikhail. A Cultura Popular na Idade Média e no Renascimento: O Contexto de Rabelais. Trad. Yara Frateschi Vieira: São Paulo/Brasília: Hucitec/Universidade de Brasília, 1987.

BARROS, José D'Assunção. Heresias entre os séculos XI e XV: Uma revisitação das fontes e da discussão historiográfica - notas de leitura. Revista Arquipélago (Revista da Universidade dos Açores - Portugal). 2007-2008.

BETHENCOURT, Francisco. O imaginário da magia - feiticeiras, salutadores e nigromantes no século XVI. Lisboa: Projeto Universidade Aberta, 1987.

DUBY, Georges. Heresias e Sociedades na Europa Pré-Industrial, séculos XI-XVIII. In:

Idade Média - Idade dos Homens. São Paulo: Companhia das Letras, 1990. 
ELIADE, Mircea. Ocultismo, Bruxaria e Correntes Culturais: ensaios em religiões comparadas. Belo Horizonte: Interlivros de Minas Gerais Ltda, 1979.

FOUCAULT, M. Resumo dos cursos do Collège de France (1970-1982). Rio de Janeiro: Jorge Zahar Ed.,1997.

GIGANTE, Valério. Rivista Adista, 15-03-2010. Tradução Moisés Sbardelotto. In: http://www.ihu.unisinos.br/index.php, acesso 03/06/2011.

GINZBURG, Carlo. O Queijo e os Vermes: o cotidiano e as idéias de um moleiro perseguido pela Inquisição. São Paulo: Companhia das Letras, 1987.

IAN/TT (Instituto Arquivo Nacional/Torre do Tombo), Inquisição de Coimbra, processo 6808: Margarida Gonçalves.

IAN/TT, Inquisição de Évora, processo 6823: Maria Simões.

LA VALLE, Raniero. Il Manifesto, 02-04-2010. Tradução Moisés Sbardelotto. Disponível em: http://provocacoesteologicas.wordpress.com, acesso 02/06/2011.

Le Dictionnaire des Inquisiteurs (Valence, 1494). Louis Sala-Molins (direção). Paris : Galilée, 1981.

LOPES, Edward. Discurso literário e dialogismo em Bakhtin. In: BARROS, Diana Pessoa de; FIORIN, José Luiz (Orgs). Dialogismo, polifonia, intertextualidade:em torno de Bakhtin. São Paulo: EDUSP, 2003.

MAZZI, Enzo. Il valore dell'eresia. Roma: Ed. Manifestolibri, 2010.

Manuel des Inquisiteurs de Nicolau Eymerich e Francisco Pena (Avignon, 1376 e Roma, 1578). Louis Sala-Molins (introdução, tradução e notas). Paris: Mouton, 1973.

SALLMANN, Jean-Michel. Les sorcières fiancées de Satan. Paris: Gallimard, 1989.

Recebido: $22 / 02 / 2012$

Received: 02/22/2011

Aprovado: 02/07/2012

Approved: 07/02/2012 